ISSN: 2036-5438

\title{
A comparison of existing forums for interparliamentary \\ cooperation in the EU and some lessons for the future
}

by

Diane Fromage*

Perspectives on Federalism, Vol. 10, issue 3, 2018 


\begin{abstract}
Interparliamentary conferences and other permanent forums for interparliamentary cooperation are blossoming in the European Union. Following more or less lengthy negotiations between national and European parliamentarians, two new conferences and a new joint parliamentary scrutiny group for Europol have been created since 2012. Against this background, this article examines to what extent the Joint parliament scrutiny group is comparable to the previously existing interparliamentary conferences. Beyond that, it asks the question as to whether any better-defined guidelines or procedures could be adopted to rationalise the process of creation of new forums for interparliamentary cooperation. It makes some concrete proposals in that direction.
\end{abstract}

\title{
Key-words
}

Interparliamentary cooperation, European Union, national parliaments, European Parliament, democratic accountability 


\section{Introduction}

Initiatives for cooperation between national parliaments (NPs) and the European Parliament (EP) are nothing new (Maurer-Wessels 2001: 453f., Neunreither 2005). They became particularly necessary when the organic link between Member States legislatures and the European Parliamentary Assembly (largely) disappeared with the introduction of the direct European elections in 1976. ${ }^{\mathrm{I}}$ In fact, the oldest forum for interparliamentary cooperation, the Speakers' Conference, initiated in 1963, only started meeting regularly from 1975 onwards. Despite the fact that the EP showed willingness to tighten the relations between its sectoral committees and those of NPs (Spènale report 1975), ${ }^{\text {II }}$ the first formalized permanent initiative in this sense was taken in 1989 when the Conference of Parliamentary Committees for Union Affairs of Parliaments of the European Union (COSAC) was created. The first time national parliaments were ever mentioned in the Treaties, in the Declaration nr 13 on the role of national parliaments in the European Union annexed to the Treaty of Maastricht, both the exchange of information and the contacts between EP and NPs were considered to have to be 'stepped up'. Another Declaration ( $\mathrm{nr}$ 14) was specifically dedicated to the 'Conference of the parliaments', i.e. the Assizes, but these were only ever celebrated once in 1989, i.e. before the adoption of the Declaration, so that these dispositions were never applied in practice. By contrast, in the Treaty of Amsterdam, only COSAC was mentioned in the Protocol on the role of national parliaments in the European Union (EU); interparliamentary cooperation in itself was not referred to. In the Treaty of Lisbon, interparliamentary cooperation is attributed a much more important function as it is defined as one of the means by which 'national parliaments contribute actively to the good functioning of the Union' (art. 12 Treaty of the EU (TEU)). With the Lisbon Treaty therefore, interparliamentary cooperation between NPs and EP was attributed a whole new, enhanced, status (for more details on the historical evolution, see Casalena, Fasone, Lupo 2013). In Protocol nr 1 on the role of national parliaments in the European Union, a title is specifically dedicated to interparliamentary cooperation. This Protocol not only contains a reference to COSAC (though the Protocol now indirectly refers to ' $[a]$ conference of Parliamentary Committees for Union Affairs', art. 10); it also prescribes that '[t]he European Parliament and national 
Parliaments shall together determine the organisation and promotion of effective and regular interparliamentary cooperation within the Union' (art. 9, emphasis added). Regularity and effectiveness are prescribed for the first time.

In this context, interparliamentary conferences (IPCs) and permanent formalized forums of interparliamentary cooperation have been blossoming since the entry into force of the new Treaty. No less than two new conferences and one joint parliamentary group have been created since 2012: the Interparliamentary Conference on Common Foreign and Security Policy and Common Security and Defence Policy (CFSP Conference) dating from 2012, the Conference on Economic Stability, Coordination and Governance (SECG Conference) of 2013 and the Joint Parliamentary Scrutiny Group for Europol (JPSG) instituted in 2016, and which adopted its rules of procedure in March 2018. The JPSG is arguably not an interparliamentary conference as clearly stated in the conclusions adopted at the Speakers' conference meeting held in Bratislava in April 2017: ${ }^{\mathrm{III}}$ the JPSG is meant to be a scrutiny and monitoring body, as opposed to an inter-parliamentary conference'. Several of its features, such as the fact that it regularly brings together MPs and MEPs, its format or the frequency of its meetings are, nevertheless, identical to those of IPCs. Taking due account of these differences, the interparliamentary conferences and the JPSG will be referred to here as 'forums for interparliamentary cooperation'.

Other such forums could, additionally, still be established in the near future, to monitor Eurojust for example, ${ }^{\mathrm{IV}}$ and interparliamentary cooperation has important potential in numerous areas, such as the budgetary domain for instance (Fasone, 2018). Yet, even where a new forum is instituted little time after the creation of the previous one, rules concerning inter alia the composition and the organization of the meetings are not reproduced and are, instead, the object of sometimes heated negotiations (this happened for instance when the SECG Conference was set up: Cooper 2014). By contrast, even where the Treaty basis differs as is the case with the JPSG, differences relative to other forums for interparliamentary cooperation appear to be much less important than one could have expected given their different standings in the Treaties. This difference does not however prevent any comparison between the JPSG and interparliamentary conferences. As will be shown here, the JPSG does, in some respects, very much resemble the existing interparliamentary conferences and can thus be compared to them. Since Conferences have 
been existing much longer than the JPSG, they additionally offer an interesting point of comparison for the recently created Scrutiny Group.

Against this background, this article aims at examining on which grounds the recently established JPSG really differs from the pre-existing IPCs and to what extent the IPCs are comparable to one another. Such analysis serves a more general reflection on the future of formalized permanent interparliamentary cooperation (i.e. whether for instance a model for (future) interparliamentary forums can be designed) and, more generally, whether these attempts can be rationalised (i.e. whether lengthy negotiations can be avoided by establishing some basic procedures guiding the establishment of new forums and whether the existing forums' functioning can be optimised). For the sake of comparability, the JPSG is contrasted with the three existing conferences for interparliamentary cooperation at committee level; the Speakers' Conference is hence only mentioned for reference. This comparison will fill in a gap in the literature on interparliamentary cooperation: whereas much interest has been devoted to the individual conferences, they are rarely compared with one another (Cooper, forthcoming).

In this article, the focus is set exclusively on permanent formalized forums for interparliamentary cooperation between national parliaments and the European Parliament (EP). Instances that bring together national parliaments only or that take place on an informal basis will therefore not be examined. Joint parliamentary meetings organised by the EP and national parliaments, Interparliamentary committee meetings convened by the EP, and the meetings held by the parliament of the Member State holding the presidency of the Council (presidency parliament) will not be taken into account either since they operate under a different logic. Among other things, they convene on a more ad hoc basis, i.e. there is not necessarily a continuity in the parliamentary committees involved or in the themes addressed which depend on the interests of a specific EP committee or on the presidency parliament at a certain moment in time. Additionally, the two conventions (summoned in 1999 and in 2001 to draft the Charter of fundamental right and to debate on the future of Europe respectively) are not considered either because those were punctual initiatives that also followed a different dynamic. ${ }^{\mathrm{V}}$

This article is structured as follows. First, commonalities among the existing forums are examined (II). An analysis of the existing differences follows (III). This allows for an 
evaluation as to whether a more rationalised framework for (future) interparliamentary conferences can and ought to be designed (IV).

A reflection as to the aim of interparliamentary cooperation in itself should be conducted prior to comparing the JPSG to the other three IPCs. Research in political science has, for instance, identified several aims of interparliamentary cooperation: the exchange of best practices and information and the 'enhanc[ement of] the democratic legitimacy of EU politics through participation and deliberation (Hefftler-Gattermann 2015: 95). The perceived function of interparliamentary cooperation largely varies among NPs though, with some of them considering that it is only suited for debates on general issues whereas others conceive of it as a potential means to ensure the democratic legitimization of EU actions (Esposito 2014: 134). In other words, interparliamentary conferences are generally perceived as assuming the functions of 'discussion forums' or those of 'oversight bodies', or a mixture thereof (Cooper forthcoming). These differences in the objectives set for those efforts for interparliamentary cooperation matter, as they shape parliamentary preferences on issues such as the adoption of conclusions or the absence thereof, the adoption procedures (consensus vs unanimity) and the aim of the cooperation (e.g. whether it is meant to enhance accountability or not) (Cooper forthcoming).

As per the Treaty, only COSAC has the clear aim to allow for the exchange of information and best practices (art. 10 Protocol 1). The generic specific legal basis - art. 9 Protocol 1 - and article 12 TEU simply set 'effective and regular' interparliamentary cooperation between NPs and the EP as a goal (art. 9). However, the conferences' rules of procedure may define their individual objectives more clearly and, as will be shown here, practice may differ slightly from those formal rules.

Cooperation can, additionally, be said to be in national and European parliaments' interest as it can help them overcome the 'informational asymmetry' they suffer from vis-àvis their executives due to the 'executive dominance issue' (on this deficit: Curtin 2014: 15, in CFSP in particular: Huff 2015: 397). Some have argued that as per the Treaty (art. 10 TEU), NPs' main role in the EU is (still) to hold their respective government to account; instruments of direct participation attributed by the Treaty are hence ancillary to this primary role (Esposito 2014: 139). This may be true in practice where one observes that NPs' participation in EU affairs is still focused on their own government, in particular in 
those Member States in which parliaments have strong means of influence on their governments' position (for instance: Denmark, Finland or German Bundestag). These parliaments are typically not interested in mechanisms such as the Political Dialogue with the European Commission or the Early Warning System for the control of the respect of the principle of subsidiarity. This, however, does not mean that interparliamentary cooperation should not be strengthened and should not offer an opportunity to parliaments to debate collectively with the Commission, thereby controlling its actions softly. Recent trends towards an intensification of attempts of interparliamentary cooperation of all sorts in fact point to a thirst for more contacts. Finally, interparliamentary cooperation has more virtues: it has contributed to the diffusion of models and best practices among parliamentary chambers (Buzogány 2013, Dias Pinheiro 2016) and has fostered cooperation at administrative level (Esposito 2014: 181; see also Fistilis in this Special Issue).

\section{Commonalities between the JPSG and IPCs}

Common points among these forums relate to a series of aspects: their formalization; the frequency, the size and the format of their meetings; the EP's role within them and a functioning based on consensus.

The most obvious common element among these five forums of interparliamentary cooperation considered as a whole is their formalization if compared to other interparliamentary meetings that take place on an ad hoc basis (inter alia, Joint parliamentary meetings, Interparliamentary committee meetings, presidency parliaments meetings). They all function on the basis of precise rules of procedure. ${ }^{\mathrm{VI}}$ Additionally, the Speakers' Conference also played a crucial role at the time of their establishment (Fasone 2016, Speakers' Conference 2017).

While the IPCs/JPSG convene on a regular basis, those meetings all take place only occasionally: once a year for the Speakers' conference, twice a year for the CFSP and the SECG conferences and the JPSG, and four times a year for COSAC, although two of these four meetings only bring together the chairpersons of the EU committees. Also, the size and the formats of these meetings is similar: they take the form of large assembly meetings where each speaker can only intervene shortly and where real debates are consequently 
practically hindered (Dias Pinheiro 2016: 307), unless if for instance smaller parallel sessions are organised. The JPSG only allows NPs to send four delegates each, which is less than they can send to CFSP and COSAC plenary meetings for instance (in which cases they can send six delegates each). Still, this will make up for a large assembly of roughly 120 persons if all NPs send complete delegations. It will admittedly have to be seen whether all NPs really send as many MPs as they can as the experience of the pre-existing interparliamentary conferences tells us that they rarely do (on the CFSP Conference: Wouters and Raube 2017: 288; on the SECG Conference: Fromage 2018). The second JPSG meeting held in March 2018 was particularly important since its rules of procedure were scheduled to be adopted, after no consensus could be reached at the first meeting. This notwithstanding, neither did all national parliaments send MPs - the Finnish parliament did not and in some bicameral parliaments, only one chamber was represented -, nor did they all send the number of MPs they are allowed to send (only 75 participated out of the 112 that may attend). ${ }^{\text {VII }}$ Additionally, given the fact that this time there is really something to gain from these interparliamentary meetings since the JPSG is a 'scrutiny and monitoring body', it could be expected that MPs would be keener on participating.No firm conclusions should be drawn on the basis of the two meetings organised thus far. Their active participation could, in fact, contribute to them pursuing an adequate exercise of their rights of scrutiny and it could lead to a potential improvement of their sometimes scarce information as they could benefit from the EP's 'higher expertise and full-time European focus' (Ruiz de Garibay 2013: 90) and from the fact that some NPs are better informed than others (on their different rights of access to EU documents: COSAC 2012). In fact, information deficits have been a concern for parliaments for long. ${ }^{\text {VIII }}$ It will have to be seen whether MEPs, whose control over Europol has improved since it became an EU agency (Ruiz de Garibay, 2013: 88), are allowed and ready to share their knowledge with their national counterparts.

Another commonality which affects all forums for cooperation at committee level is the prevalent role of the European Parliament. In COSAC, its privileged position is less pronounced. It is always part of the Troika together with the previous, the current and the upcoming presidency parliaments, which gives it a more important status. However, it may only send six delegates to each of the plenary meetings - like NPs - (art. 3.1 COSAC Rules of procedure) and none of the four yearly meetings take place in its premises: they always 
take place in the parliament of the Member State holding the rotating Council presidency (art. 2.1). This is also the case of the CFSP conference meetings at present, but in this case, its rules of procedure do foresee the possibility that these meetings take place in the EP's premises (art. 3.1). The IPC 'shall [also] be presided over by the Presidency Parliament, in close cooperation with the European Parliament (art. 3.2, emphasis added). In the case of the SECG conference, one of the two yearly meetings must take place in the EP, and it acts as a co-convener then (art. 3.1. SECG Rules of procedure and Annex to the Bratislava Speakers' Conference conclusions point 3). ${ }^{\mathrm{IX}}$ In the JPSG, the second meeting of every year is organised in the EP's premises and the EP is a co-convener of all meetings. In fact, reproducing the Treaty, the new Europol Regulation ${ }^{\mathrm{x}}$ clearly gives a predominant role to the EP. For instance, it states that '[p]ursuant to Article 88 TFEU, the scrutiny of Europol's activities shall be carried out by the European Parliament together with national parliaments' (emphasis added, Art. 51-1 Europol Regulation). This differentiation is arguably legitimate given the status of Europol as an EU agency and given the intrinsic European nature of Europol's actions. Nevertheless, this differentiation in NPs' and the EP's status was much less clearly entailed in the principles adopted by the Speakers in April 2017 in preparation for the approval of the Conference's rules of procedure. For instance, the co-presidency between the EP and the Presidency parliament was established for all meetings. It can nevertheless be expected that the EP will play an important role and contribute to the formalization of the Group.

Finally, an important similarity exists with regard to the functioning of these conferences. Only COSAC may derogate from the obligation to adopt its contributions by consensus (art. 7.5 COSAC rules of procedure). Indeed, where no consensus can be found, it may proceed with a vote by qualified majority (3/4 of the vote cast). The question of the topics addressed by the CFSP and the SECG conferences could be the reasons why NPs were not ready to agree to majority voting procedures; in fact, an attempt to amend the rules of the CFSP Conference to introduce qualified majority voting failed in 2014 because it would have gone against the principles approved by the Speakers in Warsaw in 2012 (Cooper 2017: 239). Political salience is likely to be an even more important element in the setting up of the JPSG. Another explanation could also be one of generation: COSAC is an interparliamentary initiative of first generation, created at a time when Member States were much less numerous and much more homogeneous and when the idea of a second 
chamber at European level was much debated. Additionally, even if opinions sometimes slightly differ, COSAC has been subject to recurrent criticism since its creation (see the part dedicated to COSAC in Lupo and Fasone 2016) so that perhaps when the CFSP and the SECG were created over the past years, one tried not to reproduce the functioning of COSAC to avoid facing the same difficulties.

In any event, the JPSG and IPCs not only present certain similarities; several differences also exist amongst them.

\section{Differences between the JPSG and the IPCs}

Differences between the JPSG and the IPCs exist mostly in five regards: as to their composition, their Treaty basis and their degree of formalization visible in the instruments in which the norms that govern the forums are contained, in the regularity with which the same MPs and MEPs attend meetings, and as to their (formal) purpose.

The composition of these Conferences and of the JPSG indeed differs largely. The Speakers Conference and COSAC establish full equality between the EP on the one hand and NPs on the other. On the contrary, the CFSP Conference counts with 16 MEPs vs 6 MPs per NP, the JPSG has 16 MEPs and 4 delegates per NP and the SECG Conference does not define any rule in this regard because no agreement could be found among its members. MEPs thus outnumbers individual NPs' delegations in all forums but COSAC. The issue of the size of the different delegations is less relevant where conclusions are adopted by consensus though (Dias Pinheiro 2017: 95).

The difference between the JPSG and the other forums can also be related to their different Treaty bases. NPs' role in the control of Europol (and of Eurojust) is specifically mentioned in article 12 Treaty of the European Union (TEU) on the participation of national parliaments (c)) and in article 88-2 b) Treaty on the Functioning of the EU (TFEU). Indeed, that article prescribes that 'These regulations [on Europol] shall also lay down the procedures for scrutiny of Europol's activities by the European Parliament, together with national Parliaments'. By contrast, the other conferences are based on the general reference to interparliamentary cooperation with the European Parliament (art. $12 \mathrm{f}$ TEU) as developed in the Protocol on the role of national parliaments annexed to the Treaties. Article 9 of Protocol no. 1 arguably indirectly refers to COSAC (the explicit 
reference contained in the Amsterdam Treaty was removed in the Lisbon Treaty) but this reference in a Protocol cannot be compared to the explicit reference to Eurojust and Europol contained in the Treaty itself and more specifically in the article dedicated to NPs' participation in the EU. Additionally, the content of the provisions differs since article 12 TEU explicitly mentions national parliaments contributing to the good functioning of the Union by 'taking part, within the framework of the area of freedom, security and justice, in the evaluation mechanisms for the implementation of the Union policies in that area, in accordance with Article 70 of the Treaty on the Functioning of the European Union, and through being involved in the political monitoring of Europol and the evaluation of Eurojust's activities in accordance with Articles 88 and 85 of that Treaty' (emphasis added). As per article $88 \mathrm{TEU}$, this regulation was adopted following the ordinary legislative procedure and was subject to the subsidiarity check of national parliaments who adopted several reasoned opinions and expressed their views on the form that interparliamentary cooperation should take. The EP was set on an equal footing with the Council during the procedure that led to the new Europol Regulation adopted in 2016. During the legislative procedure, the EP's and NPs' role was undoubtedly improved and broadened if compared to the original Commission proposal. The original proposal by the Commission ${ }^{\mathrm{XI}}$ indeed contained scarce dispositions for parliamentary scrutiny. Chapter IX dedicated to 'parliamentary scrutiny' provided for the direct transmission of information to both EP and NPs and for the possibility for them to ask the Chairperson of the Management Board and the Executive Director to appear before them. Furthermore, it was established, in generic terms, that 'Parliamentary scrutiny by the European Parliament, together with national Parliaments, of Europol's activities shall be exercised in accordance with this Regulation'. The EP then requested in first reading ${ }^{\mathrm{XI}}$ that this Chapter be dedicated to 'Joint parliamentary scrutiny' (emphasis added) and it introduced the JPSG. It is interesting to note that despite this (generous) move which, in fact, reproduced earlier proposals for interparliamentary cooperation (Ruiz de Garibay 2013: 91), it then sought to establish its predominance by suggesting that the JPSG should be

established within the competent committee of the European Parliament, comprising the full members of the competent committee of the European Parliament and one representative of the competent 
committee of the national parliament for each Member State and a substitute. Member States with bicameral parliamentary systems [would] instead be represented by a representative from each chamber.

All meetings also always had to take place in the EP's premises and be co-chaired by the chairs of the responsible committee of the EP and the presidency parliament. After the interinstitutional negotiations that followed, it was agreed that the organisation and the rules of procedure would be defined by the EP and NPs at a later stage, ${ }^{\text {XII }}$ thereby conferring, once again, a constitutional function to the Speakers' Conference in this foundational moment. In parallel to this procedure, NPs also expressed their views by means of contributions to the informal Political Dialogue with the Commission and by means of reasoned opinions; those are useful to understand the different positions that later on had to be reconciled in the Speakers' Conference. For instance, the Cypriot parliament expressed its wish that 'the provisions to be finally adopted [should] ensure the role and the effective participation of the national Parliaments together with the equally important role of the European Parliament. The principle of parity should be secured by effective means' ${ }^{\text {XIV }}$ These questions were also debated at the Speakers' Conference of April 2014 where some speakers (Polish Senate, Irish Senate and Hungarian parliament) in fact advocated the creation of a 'full-blown interparliamentary conference for the whole policy field of JHA [Justice and Home Affairs...] modelled on the formula of the CFSPCSDP and SECG Conferences, in that it would replace the existing meetings of chairpersons, meet twice a year, and be co-hosted and co-presided over by the EP and the Presidency Parliament' (Cooper 2017: 233). Interestingly, the EP representative firmly rejected this proposal at the time (ibid.). The formula finally agreed upon by the Speakers in 2017 therefore appears to be a compromise between the position of (some) NPs and the $\mathrm{EP}$ and is also the result of long-standing discussions that started in 2001.

By contrast, the other initiatives for interparliamentary cooperation are a development of the more general reference to their contribution 'by taking part in the interparliamentary cooperation between national Parliaments and with the European Parliament, in accordance with the Protocol on the role of national Parliaments in the European Union', as detailed in articles 9 and 10, Protocol 1. It is interesting to note however that this notwithstanding, COSAC has sought to gain a special status for itself on the basis of the (now indirect) reference to it contained in article 10 (Esposito 2014:159). 
As a consequence of this different treaty basis, the rules of procedures of the other Conferences were not approved following the legislative procedure unlike what happened in the framework of the establishment of the JPSG. The Speakers have recently gained importance in this framework (Fasone 2016: 278) since they now 'oversee the coordination of interparliamentary EU activities' (Art. 2-3 Guidelines for interparliamentary cooperation), while in the process of COSAC's creation their role had been more limited (Cooper 2017:236). The question even arose as to whether the Speakers should not even approve the SECG Conference's rules of procedure (Speakers' Conference meeting of Rome, 2015). This eventually did not happen but the Speakers approved some guidelines which constrained the different forums in the definition of their rules of procedure, and will continue to do so in the future. It follows from the above that the JPSG distinguishes itself from the others most in terms of the degree of formalization (as opposed to permanent initiatives whose anchoring in the EU institutional framework and functioning is much less (strictly) defined) since it can rely on a clear Treaty basis developed later on in a Regulation. COSAC too is quite a formalized forum if compared to the other three conferences. It has an (indirect) recognition in the Treaties (art. 9 protocol 1) and was even directly referred to under the Treaty of Amsterdam. COSAC's rules of procedures are published in the EU Official Journal whereas the other sets of rules are not. Additionally, it has a secretariat composed of one permanent member and members delegated by the presidency parliaments for 18 months. This secretariat is hosted by the EP in Brussels, which not only contributes to the good functioning of the Conference but also allows for a good circulation of the information between the Conference and NPs thanks to their representatives in Brussels (further on this: Högenauer-Neuhold-Christiansen 2013: 51-68). Contrary to this, the secretariat of the other conferences is the responsibility of each presidency parliament which is not an ideal solution, especially as the timespan between each Member State's presidency has expanded dramatically since the latest enlargements. This means that continuity in the institutional practice and culture is missing and also that the risk exists that the topics addressed change rapidly on the basis of each Member State's priorities. Where it is involved, the EP can contribute to the smooth functioning of the Conferences but a common secretariat for the formalized initiatives for interparliamentary cooperation could in this regard prove useful (Fromage 2016) and has in fact been envisaged by (some) NPs in the past (Fryda 2016: 313). The secretariat of COSAC may not 
assume this task for legal and practical reasons: COSAC's rules of procedure clearly limit its role to supporting that interparliamentary conference (art. 9 COSAC rules of procedure) and it also already has numerous tasks to fulfil. However, it could be reformed and expanded to be in a position to support all conferences and to ensure a good coordination among all these initiatives. The problem is of course the additional resources needed since not all national parliaments have always contributed to COSAC's budget (contributions take place on a voluntary basis (art. 9.5 COSAC rules of procedure)). If the EU budget were to be reformed and if it were to have larger own resources, some could be dedicated to this purpose since after all these initiatives are of general interest, whatever the function - 'discussion forum' or 'oversight body' - of those forums. Others have additionally suggested that representatives from the different forums could be permanently invited to participate in the different IPCs'/JPSG's meeting. This would avoid duplications, develop trust, and ease dialogue and exchanges of information (Dias Pinheiro 2016: 310). This idea too bears important potential: it could easily be envisaged that a representative of the common secretariat (or of the presidency parliament until its establishment) would serve as trait d'union between the different forums.

Beyond the question of the (large) size of the forums, and the limited time for interventions this inevitably allows, other factors such as the necessary expertise and interest, and the frequent changes in the identity of the participants naturally also play a role in allowing those forums to work effectively and potentially exercise some form of scrutiny. At COSAC and in the CFSP and the SECG Conferences, no recommendation exists in relation to the opportunity for the same delegates to participate in the meetings, and they do vary in practice. By contrast, for the first time ever regularity in the identity of the participants is clearly called for by the guiding principles approved by the Speakers in 2017 which read: 'Where possible, members of the JPSG should be nominated for the duration of their parliamentary mandate'.

The overall purpose of COSAC, the CFSP Conference and the SECG Conference is also identical, i.e. to exchange information and best practices, whereas the purpose of the JPSG differs. Despite the introduction of the practice following which the responsible Commissioner commonly participates in the conferences' meetings, according to their rules of procedure, IPCs should not serve to hold the Commission or any other body to account but, more modestly, allow for the exchange of information and best practices among 
parliaments which NPs and the EP will, in turn, be able to use individually in their domestic scrutiny exercise. The SECG Conference is arguably slightly different from COSAC and the CFSP Conference in that its Rules of procedure set the specific goal of 'contribut[ing] to ensur[ing] democratic accountability' to this exchange of information and best practices:

\footnotetext{
'The Interparliamentary Conference on SECG shall provide a framework for debate and exchange of information and best practices in implementing the provisions of the Treaty in order to strengthen cooperation between national Parliaments and the European Parliament and contribute to ensuring democratic accountability in the area of economic governance and budgetary policy in the EU, particularly in the EMU' (art. 2.1, emphasis added)
}

It is, however, unclear how this should take place and, most importantly, who should be tasked with ensuring democratic accountability, i.e. the specific part of this provision does not refer to the Conference but to the debates and the exchange of information and best practices contributing to ensure accountability. This somewhat vague formula is, in fact, the result of a compromise between those who wanted to make the SECG an 'oversight body' and those who favoured a less ambitious 'discussion forum' (Cooper forthcoming). Art. 13 TSCG does not shed any light on this matter as it simply foresees that 'the European Parliament and the national Parliaments of the Contracting Parties will together determine the organisation and promotion of a conference of representatives of the relevant committees of the European Parliament and representatives of the relevant committees of national Parliaments in order to discuss budgetary policies and other issues covered by this Treaty' (emphasis added). By contrast, COSAC shall 'promote the exchange of information and best practice between national Parliaments and the European Parliament, including their special committees' (art. 10, Protocol 1, included in art. 1 COSAC Rules of procedure too). The CFSP Conference clearly excludes any accountability mechanism at EU level as its sole purpose is to 'provide a framework for the exchange of information and best practices in the area of CFSP and CSDP, to enable national Parliaments and the European Parliament to be fully informed when carrying out their respective roles in this policy area' (emphasis added, art. 1 CFSP Conference Rules of procedure). Hence, on the one hand, we observe a progressive change over time - the SECG Conference was created last -, i.e. a 
shift from a 'first generation' (COSAC) to a 'second generation' (CFSP and CFSP Conferences; JPSG) of IPCs (Fromage 2015; Gómez Martos 2016: 322). We also notice differences depending on the policy area concerned and despite its generalist character, COSAC has recently been found to be stronger than the CFSP and the SECG Conferences, inter alia because it has a permanent secretariat and can resort to qualified majority voting (Cooper forthcoming).

The present analysis would, however, not be comprehensive if it did not take practice into account. Despite those formal rules, one can indeed observe that ' $[$ t]he [CFSP] Conference can assist national parliaments and the EP in holding CFSP/CSDP decisionmakers accountable by providing throughput legitimacy' (Wouters-Raube forthcoming): the High Representative of the Union for foreign affairs and security policy is invited to participate in the Conference's meetings, which normally provides MPs and MEPs with an opportunity to interact with her thereby increasing accountability levels. Additionally, the Conference's non-binding conclusions have also been used as means of scrutiny, since parliaments have used them to pass on some judgements on policy developments (Wouters-Raube forthcoming). The SECG Conference by contrast has never adopted conclusions after its rules of procedure were approved (Cooper forthcoming) and it therefore has not used this instrument to voice a common opinion. The responsible Commissioner(s) do take part in the meetings though. Thus, the CFSP Conference and the SECG Conference offer some space for the beginning of some form of collective parliamentary oversight even if, in particular in the SECG Conference, some improvements in their functioning are still needed (Griglio and Lupo 2018).

On the other hand, we are, in any case, far from the comprehensive role the Treaty of Maastricht had attributed to the Assizes (albeit in a non-legally binding declaration) as it foresaw that 'The Conference of the Parliaments w[ould] be consulted on the main features of the European Union, without prejudice to the powers of the European Parliament and the rights of the national parliaments. The President of the European Council and the President of the Commission w[ould also] report to each session of the Conference of the Parliaments on the state of the Union.' As stated before, those far-reaching rights - potentially included to please the French who have been advocating the creation of a second EU parliamentary chamber for long_ ${ }^{\mathrm{Xv}}$ were never used in practice due to the EP's over-representation they had entailed (Gómez Martos 2016: 321). The JPSG, on the other hand, is meant to be a scrutiny and 
monitoring body, as opposed to an inter-parliamentary conference and [it] must be able to exercise its rights of scrutiny efficiently' (emphasis added, Conclusions, Bratislava Speakers' Conference), whereas the Speakers' Conference duty is to 'safeguard[...] and promot[e] the role of parliaments and carry $[\ldots]$ out common work in support of the interparliamentary activities' and it 'shall oversee the coordination of interparliamentary EU activities' (Art. 2, Stockholm Guidelines for the Conference of Speakers of EU parliaments).

One reason for all the differences observed may be related to the different policy fields addressed: the more delicate the affected matter is, the more reluctant parliaments will be to have clearly defined rules, or decisions by qualified majority voting. This is naturally likely to vary across parliamentary parties and across Member States. The fact that the three most recent forums for interparliamentary cooperation regard intergovernmental policy areas is both a factor of increased parliamentary interest in being involved (HefftlerGattermann 2015: 108) and a sign that parliaments will be less willing to cooperate wholeheartedly, among other reasons because some of them have been guaranteed more rights than others at domestic level (Wouter-Raube 2018). Additionally, Member States' institutional positions vary across policy areas - not all of them are signatories of the TSCG for instance - so that it may be more difficult to reach a consensus between those who participate and those who do not. These differences may have arguably ruined the hopes for a kind of interparliamentary cooperation geared towards tight scrutiny from the very beginning.

In delicate matters in particular, parliaments may also have a different position vis-à-vis the EP's involvement and may have additionally different ideas of what the purpose of those attempts for more interparliamentary cooperation should be. The EP is more reluctant to cooperate on an equal footing with NPs in the domains in which it itself is not in a secure institutional position; this is particularly true of the economic and the CFSP domains and long held for the control of Europol too (Fromage 2015). Similar reluctance may also be found on Member States' side though, since they are less ready to cooperate when the affected matters are more closely linked to their sovereignty. In comparison, COSAC appears to be a rather (or a more) inoffensive, generalist, forum, at least at present, and it is thus easier for all, NPs and EP, to have equal rights. 


\section{Towards the rationalisation of interparliamentary cooperation initiatives?}

It results from the above that no model for permanent formalized interparliamentary cooperation has emerged so far.

The diversity that exists among the different forums is problematic for a number of reasons. First, it may be difficult to differentiate among the different initiatives and their individual rules, which creates problems of visibility and clarity, probably even for MPs, let alone for citizens. When a new structure is created and new rules need to be defined again fully, an incredible waste of resources and time may occur, as it happened when the SECG Conference was instituted. It would be much easier if a basic model, or stronger common rules and procedures at least, were established. The Guidelines for interparliamentary cooperation approved in 2008 do exist, but they do not seem to be suitable to govern the new initiatives for interparliamentary cooperation, not least because they remain superficial and were adopted pre-Lisbon.

There are issues of efficiency too: as already noted, it would probably be more efficient if one secretariat for all conferences and the JPSG existed as this would ensure an adequate coordination of agendas and topics addressed, and continuity. Obviously, this secretariat should only assume a support function, just like the COSAC secretariat does at present. Interparliamentary cooperation in those frameworks should indeed remain an exchange among national and European politicians and the opportunity to further enhance the Europeanisation of the single presidency parliaments should not be missed. Some also called for the creation of a database containing all interparliamentary meetings, i.e. also beyond the conferences (Hefftler-Gattermann 2015:112). As indicated above, it is not only interparliamentary cooperation in the framework of the various conferences that has developed exponentially; this is a general trend that materialises in the organisation by EP committees of Interparliamentary committee meetings, in meetings organised within the parliamentary dimension of each presidency of the Council, and also in the organisation of meetings of parliaments of the same regions or around clusters of interest. Thus, while more re-centralisation by the means of a common database and a common secretariat is certainly most needed, it is arguably not sufficient. 
Against this background, the case is made here for an even more drastic recentralisation. As already explained, a reform in this direction should, by no means, transform interparliamentary conferences or the JPSG in meetings orchestrated, and even attended, by administrators. Even if cooperation among administrators is certainly needed and very valuable, it cannot fully contribute to the enhancement of political debates on EU questions, or to making MPs better aware and more knowledgeable of these issues. Any new initiative should thus contribute to improve the current situation in which some delegations to the IPCs are sometimes only represented by an administrator. This is natural in electoral periods, and certainly better than no representation at all, but it is also not fully satisfactory and in line with the purpose of those forums.

A secretariat common to all forums should be instituted and it should have sufficient means to ensure the efficient coordination of the different initiatives. To this end, it should, for instance, build upon and further develop the IPEX platform. ${ }^{\mathrm{XVI}}$ The recent decision to foster cooperation between COSAC and IPEX is a step in the right direction which should be further expanded. The platform could, and should, entail the details of other interparliamentary meetings hosted by the EP, the presidency parliament or any other parliament. Its focus could also be shifted to depart from the current aim to allow exchanges mostly on EU documents. Crucially, the interparliamentary forums should have a permanent venue instead of always taking place in the Member State holding the Council presidency or in the EP. Admittedly, this 'travelling circus' allows parliamentarians to get a (superficial) idea of realities in different states and familiarises them with other traditions and cultures. Nevertheless, given that there is not always continuity in the identity of the participating MPs, it can be doubted that this really has a tangible impact on their knowledge of other Member States. Furthermore, some parliaments are even too small to hold the large interparliamentary conference meetings so that other venues must be arranged. By contrast, the EP has two hemicycles and it could put the one in Strasbourg at disposal for interparliamentary meetings; a similar setting was in fact advocated by an MP during the February 2018 SECG Conference meeting. ${ }^{\text {XVII }}$. In this scenario, the EP would only use the Brussels hemicycle for its own sessions whereas the Strasbourg hemicycle would only be devoted to initiatives of interparliamentary cooperation. No special role is thus envisaged for the EP on this ground. The infrastructures would be most suited, the new enlarged secretariat could be hosted and could work in ideal conditions and this 
would, finally, put an end to the constant time-consuming and contaminating journeys by MEPs and EP staff between Brussels and Strasbourg. It can also be expected that France might be somewhat less reluctant to agreeing to the EP's sessions always being celebrated in Brussels if it gets something in return. With the recent establishment of the JPSG, five meetings of interparliamentary conferences take place each semester, seven in the first half of the year when also the meetings of the Speakers' Conference and the Secretary Generals are organised. The EP already hosts some of those; why not always hold them in Strasbourg instead. This would be efficient, save resources and contribute to develop ownership among the participating MPs especially. They would be always meeting in the same location, with the same colleagues in the case of the JPSG and perhaps also at some point in the case of the other IPCs if the added value of constant membership becomes clear to all involved. The question can be asked as to whether the interparliamentary meetings organised on the EP's and the presidency parliament's initiatives should be centralised as well. Perhaps it would be possible to try with first relocating the Conferences/JPSG and maintain the other meetings in Brussels and the presidency parliament's respectively, which would also mitigate the negative effects on MPs' knowledge of other States. These meetings take place with a different purpose in fact, they are more reduced in size and foster exchanges of views among specialists and they are, in the EP's case, events hosted by one specific committee. These reasons speak in favour of maintaining them in their current setting first, although a re-evaluation of this question should be carried out at a later point.

As for the modus operandi of the different conferences, some more detailed rules could be defined to ease the establishment of future forums for interparliamentary cooperation. The opportunity of a move towards interparliamentary cooperation by committee some have advocated (Lupo-Fasone 2016), e.g the end of large conferences to the benefit of smaller more regular meetings among committees, remains out of the scope of the present analysis. Suffice it to say here that this proposal certainly has potential and could solve some of the issues forums are currently facing. On the other hand, others have in fact considered that 'there is an emerging order of interparliamentary conferences in the EU after the Lisbon Treaty' (Cooper 2017: 228). Cooper bases this conclusion on three elements: the creation of interparliamentary conferences of the same kind, i.e. 'functionally specialized, focused on particular policy areas', created and evolving in the same manner, 
i.e. under the Speakers' Conference watch, and operating with similar logistical arrangements 'in terms of their timing and location and which parliament acts as chair and sets the agenda' (228). However, while it can arguably be considered that there is an emergence of such 'order', important differences remain as shown above. Most importantly, even if the forums for interparliamentary cooperation could be said to present certain similarities once they start to function, it is the period that precedes that matters, i.e. the fact that negotiations around the establishment of the new bodies systematically start afresh and give rise to (heated) debates.

The defining role assumed by the Speakers' Conference in the initial phase of the creation of new interparliamentary conferences now appears to be established and recognised by all involved, despite the absence of any legal basis in this sense. It should thus remain entrusted with the definition of guidelines but should not intervene in the daily management of the forums once they have been established as pointed out by Fasone (2016). The guidelines they have adopted so far were so detailed that they practically dictated the functioning of the forums. This should only happen again if parliaments are really unable to agree, otherwise it is best for the conference(s) to agree on their own rules themselves, also to prevent future difficulties deriving from the need to have the Speakers' Conference amend previous guidelines if changes are desired at a later stage. It will have to be seen how the JPSG functions with 4 MPs per delegation, i.e. whether this leaves more scope for debates to take place. Should this be the case, perhaps smaller delegations could become the norm in other forums as well even if they make political pluralism more difficult to ensure. In any case, consistency in the identity of the participants should be strived for in all conferences. Although it might not always be a realistic aim, it would be beneficial to reproduce the voting system as it exists in COSAC, i.e. consensus by default with a possibility to resort to qualified majority voting. As to the role of the EP, it is easier to define in abstracto than in concreto as each policy area is regulated by different rules that affect its competences at EU level, but safeguards should, in any case, be put in place to ensure it is not too predominant, unless it is justified as in the case of Europol. Finally, future forums should be flexible, perhaps allowing parliaments of Member States that have specific opt-ins to (also) meet amongst themselves in parallel to other larger meetings; this could for instance be useful to Eurozone parliaments. 


\section{Conclusion}

This article has compared the recently-established JPSG with other pre-existing IPCs and shown that despite a different (and stronger) Treaty basis, the JPSG presents important similarities with the IPCs. Determining whether these four conferences and the JPSG are more similar than dissimilar or the other way around is hence far from being straightforward. The assumption that the JPSG would be most different to the conferences due to its different Treaty basis, its different function and its clear statement that it is not an interparliamentary conference in any case does not seem to hold. It will have to be seen though whether, like it happens with the other IPCs, practice departs from the formal rules of procedure on which these conclusions are based.

Forums for interparliamentary cooperation all function on a permanent basis, on the basis of rules of procedure, meet occasionally in a large assembly setting. They operate on the basis of consensus, and the EP's has a predominant role within them. On the other hand, they also entail important differences, as each of them has a different composition. The JPSG has a clear, specific, treaty basis whereas the IPCs operate either on the basis of a general treaty basis (CFSP and SECG Conferences) or on that of an (indirect) reference in a protocol annexed to the Treaties. This then leads to the rules for their functioning being developed in different instruments (a Regulation vs rules of procedures adopted in accordance with guidelines of the Speakers (SECG and CFSP Conferences), or not $(\mathrm{COSAC})$ ). The regularity with which the same MPs and MEPs attend meetings also differs: in the JPSG, regularity is clearly wished for whereas no such provision exists in the framework of the other IPCs. Finally, their purpose largely varies, at least formally: only the JPSG should go beyond the mere exchange of information and best practices.

This therefore makes for a large variety in the different forums for interparliamentary cooperation, with such variety additionally sometimes being the result of lengthy, heated negotiations among European and national parliaments. The latter is problematic primarily because it is demanding on resources and delays the establishment of the different forums time and time again, whereas the former should be improved among others to reduce complexity, to enhance efficiency and transparency, and to avoid institutional discontinuity. The main solution put forward here to solve these issues is that of the creation of a stronger, common, permanent secretariat in charge of managing the schedule of all 
initiatives for interparliamentary cooperation. It would additionally make sure that overlaps are avoided. Moreover, with a view to simplifying the operations of the different forums, the EP's hemicycle in Strasbourg should be devoted to interparliamentary forums meetings, while the EP would always hold its sessions in Brussels.

To shed further light on the issues examined in this article, further research on interparliamentary forums may consider examining the role of the actors involved, in particular that of the presidency parliament in place when negotiations for the establishment of a new forum are conducted. It will also be interesting to look at whether executives are involved in any way or not, and at how the different party-political interests have played out during these negotiations. Indeed, previous research has shown that higher political party contestation over the EU leads to higher participation in interparliamentary meetings (Gatterman 2014 as cited by Hefftler-Gatterman 2015:109). Opposition parties may also be keener on the development of interparliamentary cooperation (Miklin 2013). An analysis of the role played by parliamentary administrations and of their internal dynamics could also uncover the reasons for certain choices. 
Annex

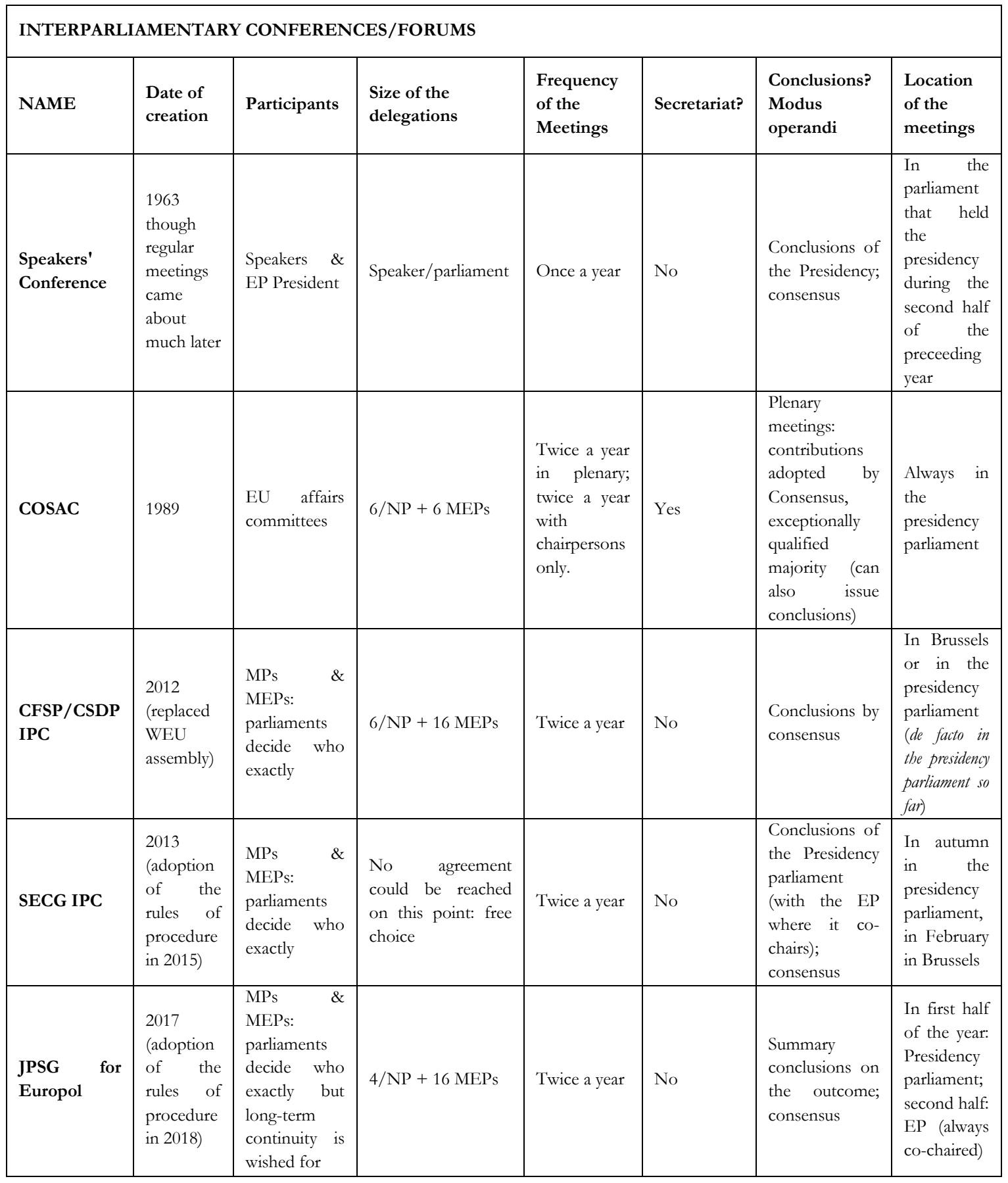

* Assistant professor of European Law, Maastricht University, The Netherlands. Diane.fromage@maastrichtuniversity.nl.

I In fact, the Treaty of Rome had foreseen from the beginning that the Council had to adopt a decision (by unanimity) introducing direct elections but this could not be achieved until almost twenty years later (Fromage 2017: 392f.). The mandatory dual mandate was suspended then, but it was still possible until its prohibition in 2002, unless Member States decided otherwise (like France did). 
II Spènale Report, DOC PE 42.070 Bur. as cited by Maurer-Wessels 2001 :456-457.

III Annex I to the Conclusions of the Presidency. Conference of speakers of the EU parliaments. Bratislava. 23-24 April 2017.

IV Article 12 c) TEU refers to both Europol and Eurojust and provides for national parliaments' involvement in 'the evaluation of Eurojust's activities in accordance with Articles 88 and 85 of that Treaty'. The opportunity to create an interparliamentary forum in this field as well has been advocated for instance by the Italian Senate (Italian Senate 2013).

$\mathrm{V}$ It should, however, be noted that the two conventions have represented interesting experiences of interparliamentary cooperation; this method has now been formally anchored in the Treaties. More on this experience (Pinelli 2016).

VI Apart from the one of the JPSG, all of these rules of procedure are available on the IPEX website ipex.eu.

VII Participants' list available on the website of the parliamentary dimension of the Bulgarian presidency (https://parleu2018bg.bg/en/events/81).

VIII Discussions about the strengthening of interparliamentary cooperation as a means to, among others, provide a remedy to information shortage have been ongoing since 2001 at least (Ruiz de Garibay 2013: 91).

IX It is interesting to note that (some) NPs were not ready to give a larger role to the EP: formally granting it the right to send a larger delegation, and thereby reproducing the CFSP Conference precedent was apparently one step too far for some NPs and explains why the size of the delegations remains undefined (Esposito 2014:168).

x Regulation (EU) 2016/794 of the European Parliament and of the Council of 11 May 2016 on the European Union Agency for Law Enforcement Cooperation (Europol) and replacing and repealing Council Decisions 2009/371/JHA, 2009/934/JHA, 2009/935/JHA, 2009/936/JHA and 2009/968/JHA.

XI $\operatorname{COM}(2013) 173$ final.

XII European Parliament legislative resolution of 25 February 2014 on the proposal for a regulation of the European Parliament and of the Council on the European Union Agency for Law Enforcement Cooperation and Training (Europol) and repealing Decisions 2009/371/JHA and 2005/681/JHA (COM(2013)0173 - C70094/2013 - 2013/0091(COD)) (Ordinary legislative procedure: first reading).

XIII Position of the Council at first reading with a view to the adoption of a REGULATION OF THE EUROPEAN PARLIAMENT AND OF THE COUNCIL on the European Union Agency for Law Enforcement Cooperation (Europol) and replacing and repealing Council Decisions 2009/371/JHA, 2009/934/JHA, 2009/935/JHA, 2009/936/JHA and 2009/968/JHA - Adopted by the Council on 10 March 2016.

XIV Opinion of the Standing Committee on Legal Affairs of the House of Representatives of the Republic of Cyprus with regard to the Joint Parliamentary Scrutiny Group on Europol's activities, 19 November 2015, available at www.ipex.eu.

$\mathrm{xV}$ See for instance on this question the French Senate's dedicated webpage: 'Un Sénat européen?' http://www.senat.fr/europe/dossiers/senat europeen.html

XVI The platform for EU Interparliamentary Exchange www.ipex.eu.

XVII The debates can be watched at: http://www.europarl.europa.eu/ep-live/en/otherevents / video? event $=20180220$-0900-SPECIAL-UNKN.

\section{References}

- Buzogány Aron, 2013, 'Learning from the best? Interparliamentary networks and the parliamentary scrutiny of EU decision-making', in Crum Ben and Fossum John Erik (ed), Practices of interparliamentary coordination in international politics. The European Union and beyond, ECPR press, Colchester, 17-32.

- Casalena Pier Giorgio, Fasone Cristina and Lupo Nicola, 2013, 'Protocol (No. 1) on the Role of National Parliaments in the European Union', in Blanke Hermann Josef and Mangiameli Stelio (eds), The Treaty on the European Union (TEU). A commentary, Springer, Heidelberg, 1529-1634.

- Cooper Ian, 2014, 'Parliamentary Oversight of the EU after the Crisis: On the Creation of the "Article 13” Interparliamentary Conference', LUISS Guido Carli School of Government Working Paper No. SOGWP21/2014. 
- $\quad$ Cooper Ian, 2017, 'The emerging order of interparliamentary cooperation in the post-Lisbon EU', in Jančić Davor (ed), National parliaments after the Lisbon Treaty and the Euro crisis. Resilience or resignation?, Oxford University Press, Oxford, 227-246.

- Cooper Ian, forthcoming, 'The Inter-Parliamentary Conferences of the European Union: Discussion Forums or Oversight Bodies?', in Raube Kolja, Müftüler Bac Meltem and Wouters Jan (eds), Parliamentary Cooperation and Diplomacy in EU External Relations, Edward Elgar, Cheltenham.

- COSAC, 2012, 'Seventeenth Bi-annual Report on Developments in European Union - Procedures and Practices Relevant to Parliamentary Scrutiny'.

- Curtin Deirdre, 2014, 'Challenging Executive Dominance in European Democracy', The Modern Law Review, LXXVII(1): 1-32.

- Dias Pinheiro Bruno, 2016, 'The role of COSAC in the changing environment of national parliaments in the EU: an identity crisis?', in Lupo Nicola and Fasone Cristina (eds), Interparliamentary cooperation in the composite European constitution, Hart, Oxford, 303-310.

- Dias Pinheiro Bruno, 2017, 'Interparliamentary cooperation between national parliaments', in Goldoni Marco and Jonsson Cornell Anna (eds), National and regional parliaments in the EU-legislative procedure post-Lisbon, Hart, Oxford, 87-113.

- $\quad$ Esposito Antonio, 2014, 'La cooperazione interparlamentare: principi, strumenti e prospettive', in Manzella Andrea and Lupo Nicola (eds) Il sistema parlamentare euro-nazionale, Giappichelli, Torino, 133-182.

- Fasone Cristina, 2016, 'Ruling the (dis-)order of interparliamentary cooperation? The EU Speakers' Conference', in Lupo Nicola and Fasone Cristina (eds), Interparliamentary cooperation in the composite European constitution, Hart, Oxford, 269-289.

- $\quad$ Fasone Cristina, 2018, "Towards a strengthened coordination between the EU and national budgets. A complementary role and a joint control for parliaments?', Journal of European Integration, XL(3): 265-279. Special issue on 'National parliaments, the European Parliament and the democratic legitimation of the European Union economic governance' edited by Diane Fromage and Ton van den Brink.

- $\quad$ Fromage Diane, 2015, 'Parlamento Europeo y Parlamentos nacionales después del Tratado de Lisboa y en un contexto de crisis: ¿un acercamiento de grado diverso según el ámbito?’, in Andrés Paz and Ugartemendia Juan-Ignacio (eds), El Parlamento europeo: ¿esta vez es diferente?, IVAP, Guipuzcoa, 223-249.

- Fromage Diane, 2016, 'Increasing Interparliamentary cooperation in the EU: Current Trends and Challenges', European Public Law, XXII(4): 749-772.

- $\quad$ Fromage Diane, 2017, 'Le Traité de Rome: source d'inspiration pour remédier au déficit démocratique européen?', Percorsi costiturionali: 389-403.

- Fromage, Diane, 2018, 'The European Parliament in the post-crisis: An institution empowered on paper only?', Journal of European Integration, XL(3), 281-294. Special issue on 'National parliaments, the European Parliament and the democratic legitimation of the European Union economic governance' edited by Diane Fromage and Ton van den Brink.

- Fryda Christiana, 2016, 'The role of the COSAC secretariat within the evolving landscape of interparliamentary cooperation: challenges for the future', in Lupo Nicola and Fasone Cristina (eds), Interparliamentary cooperation in the composite European constitution, Hart, Oxford, 311-317.

- Gattermann Katjana, 2014, National parliamentarians and inter-parliamentary cooperation: testing the effect of electoral institutions on their incentives to engage in European affairs' cited by Hefftler Claudia and Gattermann Katjana, 2015, 'Interparliamentary cooperation in the European Union: Patterns, problems and potential', in Hettler Claudia et al. (eds), The Palgrave Handbook on national parliaments and the European Union, Palgrave Macmillan, Basingstoke, 94-115.

- Gómez Martos Francisco, 2016, 'Interparliamentary cooperation in the context of COSAC. A view from the European Parliament', in Lupo Nicola and Fasone Cristina (eds), Interparliamentary cooperation in the composite European constitution, Hart, Oxford, 319-324.

- Hefftler Claudia and Gattermann Katjana, 2015, 'Interparliamentary cooperation in the European Union: Patterns, problems and potential', in Hettler Claudia et al. (eds), The Palgrave Handbook on national parliaments and the European Union, Palgrave Macmillan, Basingstoke, 94-115.

- Huff Ariella, 2015, 'Executive privilege reaffirmed? Parliamentary scrutiny of the CFSP and CSDP', West European Politics, XXXVIII(2): 396-415. Special issue 'After Lisbon: National parliaments in the European Union’ edited by Katrin Auel and Thomas Christiansen. 
- Italian Senate, 2013, 'Risoluzione della 2a Commissione permanente sulla proposta di Regolamento del Parlamento europeo e del Consiglio che instituisce l'agenzia dell'Unione europea per la cooperazione giudiziaria penale (Eurojust) (COM(2013)535)'.

- Lupo Nicola and Fasone Cristina, 2016, 'Conclusion', in Lupo and Fasone (eds) Interparliamentary cooperation in the composite European constitution, Hart, Oxford, 269-289.

- Maurer Andreas and Wessels Wolfgang, 2001, 'National parliaments after Amsterdam: From slow adapters to national players?', in Maurer and Wessels (eds), National parliaments on their way to Europe: Losers or latecomers?, Nomos, Baden-Baden, 425-475.

- Miklin Eric, 2013, 'Inter-parliamentary cooperation in EU affairs and the Austrian Parliament: Empowering the Opposition?', Journal of Legislative Studies, XIX(1): 22-41.

- Neunreither Karlheinz, 2005, 'The European Parliament and National Parliaments: Conflict or cooperation?', Journal of Legislative Studies, XI(3-4): 466-489.

- Pinelli Cesare, 2016, 'The Convention Method', in Lupo Nicola and Fasone Cristina (eds), Interparliamentary cooperation in the composite European constitution, Hart, Oxford, 57-72.

- Ruiz de Garibay Daniel, 2013, 'Coordination practices in the parliamentary control of justice and home affairs agencies: the case of Europol', in Crum Ben and Fossum John Erik (eds), Practices of interparliamentary coordination in international politics. The European Union and beyond, ECPR press, Colchester, 87103.

- Speakers' Conference, 2017, 'Conclusions of the Presidency', EU Speakers' Conference held in Bratislava on 23-24 April 2017. Available at: http://www.ipex.eu/IPEXLWEB/euspeakers/getspeakers.do?id=082dbcc55898c90b01589abbb37500fa.

- Wouters Jan and Raube Kolja, 2017, 'The many facets of parliamentary involvement and interaction in EU external relations. A multilevel tale', in Jančić Davor (ed), National parliaments after the Lisbon Treaty and the Euro crisis. Resilience or resignation?, Oxford University Press, Oxford, 281-298.

- Wouters Jan and Raube Kolja, 2018, 'Between aspirations and realities: Interparliamentary cooperation in the EU's Common Foreign, Security and Defense policies', Politique européenne, no. 59: 170-193. Special issue 'Les parlements des Etats Membres face au(x) défi(s) européen(s)' edited by Diane Fromage and Kolja Raube. 